in Research literacies and writing pedagogies for masters and doctoral writers ed Cecile Badenhrst and Cally Guerin , 2016 pub.Brill, Leiden and Boston

\title{
Agency and Articulation in Doctoral Writing: Building the Messy Research Journey into a Well-Constructed Thesis
}

\section{Gina Wisker}

\section{Introduction}

The research journey is a messy one, full of surprises, difficulties, discoveries, hard work, beginnings and some form of closure. The thesis, whether a monograph or published/publishable articles and a theorised "wrap", is well organised and lucidly articulated; it evidences consistent theories and themes; asks questions and analyses findings; presents a coherent argument and story; and is readable, its points clear, its contribution original (enough), its quality publishable (Winter, 2000; Holbrook et al., 2006; Kiley \& Wisker, 2011). In this chapter I am interested in exploring how doctoral students and supervisors transition in an iterative way between the messy rich journey and the well-built thesis, and how this well-conceptualised, well-articulated work is recognised by students, supervisors and examiners.

The role of post/graduate research is to make and contribute to new knowledge, but we only know about this new knowledge through writing. The research learning journey and the production of the written thesis are intertwined but essentially different practices requiring similar but different skills (ideas, hard work, completer finishing). The exciting messiness of the research journey must be communicated within the forms of the discipline and the expectations of a thesis. Research writing has been defined as a "complex struggle for identity in intertwined and often contradictory discourses that seems to be built into the post/graduate condition" (Kamler \& Thomson, 2006). Thesen identifies the "deep structure of post/graduate research and its central function, to make new knowledge. This will always involve profound issues of power and authority which are experienced as dilemmas" (2013, p. 105).

We only find out about decisions and discoveries, the way in which new and established thoughts are integrated, theorised and moved into being, and the discipline literature dialogue into which the new work fits, through the written form of the thesis. This could be a monograph or series of published/publishable chapters and a theorised "wrap" (the Scandinavian model). However, the skill of turning the research and its contribution to knowledge into a thesis which can communicate that contribution and its importance is one which is often assumed as natural, just acquired as part of the $\mathrm{PhD}$ process, or nurtured into being somewhat secretively.

This chapter focuses on ways in which doctoral students translate their research journey into an articulate thesis. I consider some blockages, key stages of the research and writing journey, and several strategies, including the support by supervisors which enables doctoral students to overcome transitional and troublesome moments, to move through liminal spaces and cross conceptual thresholds (Meyer \& Land, 2005) in doctoral writing. Identities as researchers and writers are developed alongside a "discoursal voice" (Ivanic, 1998; Bakhtin, 1981, 1986) by using the language of their discipline, and of doctoral level 
work, in producing a well-written thesis. Agency and articulation are essential for a confident contribution to knowledge expressed in a sound, readable thesis.

Discussions in this chapter are grounded in my experience of being a doctoral student and supervising doctoral students, working with doctoral students and supervisor development programmes (UK, Israel, Sweden, South Africa, Australasia) and from my research, which itself grew out of an interest in the ways in which doctoral students and supervisors experience and tackle issues in research learning and writing. It builds on workshop practices, re-scrutiny of the data from earlier projects $(2007-2010,2009,2012)$, and new data gathered for my current research project on doctoral student writing. Work discussed in this chapter offers insights into the ways in which doctoral students transition between the research and the writing, and in so doing identify, meet and cross conceptual thresholds in their work, leading to ownership, agency and articulation.

\section{Literature review}

Previous research into doctoral student learning has focused on the stages of the learning journey (Wisker et al., 2007-2010), communities supporting doctoral learning (Aitchison \& Guerin, 2014; Wisker, Robinson, Trafford, Warnes \& Creighton, 2003), troublesome encounters and emotional wellbeing issues (Morris \& Wisker 2011; Johansson, Strandler, Claesson, Saalman \& Wisker, 2014; Strandler et al., 2014), doctoral "orphans" (Wisker \& Robinson, 2013) and examiner practices (Holbrook et al., 2005, 2006). Research on doctoral student writing considers supportive writing communities (Harrison, 2006) and the processes of writing and its support (Aitchison, 2006, 2009). Other research focusing on academic writing suggests strategies to support doctoral students (Elbow, 1973; Murray, 2005; Kamler \& Thompson, 2006; Sword, 2009). Previous work conducted on my own and with colleagues focuses on doctoral learning journeys (Wisker et al., 2010) and the crossing of conceptual thresholds at stages in doctoral learning (Wisker \& Robinson, 2009; Kiley \& Wisker, 2009; Wisker, 2012). Conceptual threshold crossings can be seen to take place in doctoral students' work when students make learning leaps or breakthroughs in their learning, begin to fully own the research process, and identify and can articulate their contribution to knowledge and to conceptual understanding. Conceptual threshold crossing can take place at most of the stages of a research journey, including deciding on a research question, writing the literature review or theoretical perspectives chapter, and when the research experience findings and new knowledge, both factual and conceptual, are realised and translated into writing (Wisker, 2015). In recent work (Wisker \& Savin-Baden, 2009), we focused on liminal space and conceptual threshold crossing in academic writing. Once overcome and passed through, stuck moments or writing blocks were often seen to lead to not only confident expression, but also an awareness of how to capitalise on these transitional stages. One expectation and important achievement in doctoral writing is a development and expression of what Bakhtin recognises as a moment of entering an arena of power in which you have both right and skills to speak "the word of authority, of constraint, of precedent" (Bakhtin, 1986, p. 88), called "discoursal voice" (Maybin, 2001). However, I also recognise the development of such a confident, articulate voice within the discipline discourse community as a product of struggle. Doctoral students finding the "right words" to vehicle their research journey and findings, to enter the discourse community and argue their contribution with confidence are showing a facility and sense of agency that will be useful in all future research writing.

In the research journey and the writing process through to a completed $\mathrm{PhD}$ thesis, students need to be able to negotiate the rules and regulations, test and stretch the shapes and expressions, as well as the hierarchy of what is considered acceptable knowledge. For some, finding ways to express inappropriately "discredited knowledge" (Morrison 1984) which breaks boundaries and challenges is a significant part of the journey. One issue, however, is 
whose language and form is this? Whose knowledge construction? There are concerns with both the culturally inflected power politics of ways in which knowledge is constructed, and forms of expression. As an important contributor to this debate, Manathunga considers culturally inflected supervision, writing and shape of the $\operatorname{PhD}(2007,2014)$. Knowledge isn't the sole possession of a wealthy western white male few-it comes in many shapes and forms and in many instances it is indeed silenced and considered inappropriate, inadmissible, until those expressing that knowledge find their voice and confident, articulate expression, in forms which are likely to change the norms of expression. Focusing on such culturally inflected writing, Thesen (2013) reveals that providing writing support for all students is still under resourced and often absent.

Chihota (2007) defines the experience of being a post/graduate as "the post/graduate condition", which Thesen (2013), focusing on international post/graduates, elaborates as "a pervasive and extended state of being both novice and expert, deeply dependent on precedent, yet required to contribute something new and original" (Thesen, 2013, p. 105). Johnson, Lee and Green (2000) identify what Thesen calls the "fantasy" of the "autonomous self" that pervades the "western" academy - the independent scholar produced through supervision practices in the humanities and social sciences. They trace the antecedents of this autonomous self to the Enlightenment and the "reasonable man construct" (Thesen, 2013, p. 105). While we can recognise "the writing of research as an important feature in the drive to increase postgraduate enrolments", nonetheless, "writing is often not regarded as central to postgraduate pedagogy" (Thesen, 2013).

Actually, it's what we have all sought and built on-when recognised as an essential part of the enabling of dialogue in the field, entering a discussion, and the writing support a supervisor offers enables the student to do the writing rather than writing it for them, enabling the development of their own voice rather than substituting the supervisor's. We learn to offer models, to question with open questions, and nudge thinking into writing, rather than substitute our own work.

One of the roles of supervisors is enabling and supporting post/graduate students' writing to encourage the development of confidence, voices and structure, so that students' engagement with established forms of thinking will involve them in a dialogue with previous work, and their contributions to knowledge can be articulated in ways which are recognisable enough, acceptable to the academy and the discipline, and also flexible, responsive, creative enough to enable the student and their knowledge construction to make a genuinely original contribution (Wisker, 2015). Supervisors, directors of doctoral education and examiners are gatekeepers of the academic acceptability of the forms of expression and shape, but also nurture, encourage risk taking, and support, recognise and enable challenge the student; this is the excitement that's part of doing research and part of writing about that research. In operating these several roles, supervisors negotiate a balancing act between the licensed, often rather traditional, conventional and culturally inflected expression of research and bringing the new into being as a thesis ready for examination.

Margaret Kiley and Gerry Mullins (2002) built on work by Winter $(1993,2000)$ in considering what examiners define as essential in a good thesis:

\begin{tabular}{|l|l|}
\hline $\begin{array}{l}\text { A "good" thesis has... } \\
\text { - Critical analysis \& argument }\end{array}$ & $\begin{array}{l}\text { A "less than ideal" thesis has... } \\
\text { - Too much detail with lack of analysis }\end{array}$ \\
$\begin{array}{l}\text { - Confidence \& a rigorous, self-critical } \\
\text { approach }\end{array}$ & $\begin{array}{l}\text { Lack of confidence, energy \& engagement } \\
\text { by the candidate }\end{array}$ \\
$\begin{array}{l}\text { - A contribution to knowledge } \\
\text { - Originality, creativity \& a degree of risk } \\
\text { taking }\end{array}$ & $\begin{array}{l}\text { - Shoddy presentation (typos, etc.) } \\
\text { - Lack of critique of own analysis/sweeping }\end{array}$ \\
\hline
\end{tabular}


- Comprehensiveness \& scholarly approach

- Sound presentation \& structure

- Sound methodology generalisations based on opinion rather than analysis

- Inadequately or poorly expressed methodology and scope

Recent analysis of examination reports conducted by Holbrook et al. (2005, 2006) offers further information on the expectations of a coherent, well-written, articulate thesis, which represents a sound piece of research, consistent with and extending the above table and emphasising the importance of presentation (organisation, expression, coherence) and conceptual levels of thinking and contribution to knowledge. If these are an indication of the characteristics which examiners recognise as quality, supervisors need to share these expectations with students, discuss how to support them in their transitioning from the research journey to the thesis, so together they can plan the journey.

The phrasing in the chart above all deals with an expression of good research in the thesis. Critical analysis and argument can only be seen in the written (or spoken) form; for example, while "sound methodology" must underlie the research as a whole, it must also be explained and argued for in the thesis text. On the right hand side, the less than perfect thesis, the poor quality of writing is very obviously holding up any quality of thought or research practices or findings and so that "shoddy presentation" and "sweeping generalisations" are all aspects of poor expression, possibly, and inability to convey the importance of the work, its structure, aims, intentions, findings and contribution. Students are often alarmed to be informed that presentation (argument, coherence, expression, typos, etc.) might often considered as important as the conceptual, cognitive, intellectual work, and the contribution to knowledge. Is this pedantic, or is it recognition that we must be able to communicate clearly or the findings and message are lost and remain our possession alone? These concerns underlie the point of the importance of the translation of research into thesis. As supervisors, one responsibility is to make the challenges explicit, then support the transitions and translation. Thesen (2013) introduces the notion of "edgework" (Lyng, 1990) to explore "the conceptual edges at which risk and discourse operate. Edgework helps us explore risk-taking from below, from the positions of participants on the margins. It draws attention to the choices writers and reader-assessors make as they negotiate the complexities of how to write their research" (p. 107). Thus, risk taking in the research and engaged articulation are seen as intertwined. Thesen argues that for many students and supervisors, writing or supervising a thesis does have elements of distortion and contradiction (pp. 117-8): "Researchers, teachers and writers who can do the edgework have a role to play in doing the risky work of making new knowledge" (Thesen, pp. 118-9). I interpret this not just in terms of the research journey itself, but the translation from the research to the writing. Edgework is risky in that it challenges conventional thinking, but is essential to critical thinking and to conceptual threshold crossing in research and writing. It identifies boundaries and liminal spaces, and the doctoral student and supervisors can perceive, engage with and rise to the challenge of contested and troublesome knowledge to make something new, a contribution of worth.

\section{Methodology and methods}

In order to explore the experiences and perceptions of doctoral students and their supervisors on the process of transitioning effectively between the research and the writing of a thesis, I used two-stage interpretivist qualitative research. The first stage involved re-scrutiny of earlier research findings to follow up themes and traces for which there was no time or space to develop the work previously. The second, involved new focused interviews, each concerned with blocks and breakthroughs in writing the research into an articulate thesis, looking for evidence of conceptual threshold crossing and in the development of confidence 
and agency in writing. The re-scrutinising and new interviews are combined to see whether, and how, they provide evidence of ways in which students develop confidence, agency and articulation in their research learning journeys as these are translated into a thesis.

\section{Stage 1. Re-scrutiny of data from two earlier research projects}

(a) The "doctoral learning journeys" and the "parallel project" (2007-2010) into the learning journeys and conceptual threshold crossings of doctoral students in the UK across four discipline areas (n30, not science), and international doctoral students (20, including science), supervisors and examiners (n20, n16); and

(b) The "priceless"-writing project (Wisker \& Savin-Baden, 2009, n25), which looked at ways in which academic writers, including doctoral students, overcome writing blocks and move through liminal spaces to express conceptual as well as factual findings, and arguments.

Data from each project was re-scrutinised, paying particular attention to doctoral writers' and supervisors' comments relating the research journey to doctoral writing in the thesis, and experience of and success in producing articulate critical, conceptual and creative writing from their research.

\section{Stage 2. Interviews with UK and international doctoral students and supervisors}

Building on the earlier work, I conducted new, small scale, focused qualitative research using face-to-face or email interviews with UK and international doctoral students and supervisors (students n10 to date) and short face-to-face interviews with supervisors (n 15 to date, some of whom are still doctoral students), as part of a workshop series supporting the development of supervision (South Africa, Sweden, UK). These interviews explore blocks to and articulate links and transitions between research and theses, which evidence articulacy, confidence, agency and voice in doctoral writing.

Interviews in study (2) were transcribed, and data from both (1) and (2) was read through several times until themes emerged. Then these were confirmed through re-reading and examples of evidence of those themes identified in the data extracted from interviews. The data below is labelled from project $1 \mathrm{a}, 1 \mathrm{~b}$, or project 2 . Respondents have been identified by random letters in order to preserve confidentiality.

\section{Findings and educational significance}

In the analysis of data from previous research, I was sought to understand three related factors:

(1) how students and supervisors articulated the issues, problems, strategies and breakthroughs that enabled doctoral students to translate their research into articulate written work;

(2) challenges and blockages to the translation from the research into thesis writing, and the strategies, practice and support to do so (identified by students and supervisors); and

(3) breakthroughs in thinking and expression, at both conceptual and factual levels, as expressed in examples of engagement with troublesome knowledge, of moving through liminal spaces from confusion to new clarity.

Re-scrutiny of the earlier work revealed certain comments and themes, on which I built my questioning, so that the focused new work actually nudged students and supervisors to consider the issues.

Students, supervisors and examiners (who were also supervisors) were aware of the transitioning from the research to the written thesis, and four main areas of interest have 
emerged from the combined data. The early work helped define the four themes; questions for the new work then explored those themes:

- awareness of the difference between and difficulties of moving between the research and the thesis

- overcoming writing blocks through to articulation

- supervisor and other support in the transition and translation

- breakthroughs and conceptual threshold crossings (not covered in 1-3)

\section{Awareness of the difference between and difficulties of moving between the research and the thesis}

Respondents who are already practitioners commented on having an end and important outcomes in mind for their research, and finding it both a struggle and an experience which deepens and strengthens their understanding when they engage first with the underpinning theories and write about this, then the actual research and write about that:

[...] for me it is more the combination of the theoretical part and then again the outcomes whether it is for practical use or even for the like conclusions so it is like, you know, a journey that you are learning about different concepts and ideas and then building it, something more integrated out of it and then have it more but clearer. (1a, A)

Explaining her colleague's research journey and writing practices, one supervisor offered a very structured way forward, using the abstract as a map:

[...] in her research journey she was asked to write the abstract once the proposal had been done before the research had been undertaken and then use that abstract as her map so every time she is doing something and she feels that she is off track she goes back to her abstract and goes back to, in other words look at the research questions and putting the research question as a footnote on every page so that you can keep on going back to your research question and ensuring your methodology sticks to your question, that your results and your analysis speak to your question, that the theories that you're collecting and arguing with speak to your question and the body of work required for that question because we saw it more so that you don't get off track. $(2, \mathrm{~A})$

Examiners in the earlier research (Wisker et al., 2010) commented on the importance of engaging with the literature and making "a step up" through using underpinning theory and critical thinking as it appears in the writing of others, to inform students' research and writing in their theses. They could see this engagement and translation in successful theses:

Learning takes place through conforming to the institutional framework, writing and reflection and shaping of the research, at specific stages (e.g. data analysis). Transformation, illumination and revelation are key signifiers of threshold crossing. $(1 \mathrm{a}, \mathrm{B})$

This raises issues related to concerns about conformity and the silencing of different forms of expression, as explored earlier with the work of Morrison and Manathunga from very different contexts, so as we consider ways in which students translate their research writing, 
we must also be aware of the potential conservatism of the examiners-hoping that the more inappropriate conservative practice can be changed in time.

Supervisors in recent interviews comment about their support for research, and for writing in the thesis, emphasising the importance of a balance between risk and freedom in practice:

[...] there's one thing I think is very important and powerful question that we need to ask all of ourselves, is that we don't place our own map of coherency onto our students[...] to the point that it suffocates their own different ways of thinking. (2, E)

\section{Overcoming writing blocks through to articulation}

Respondents in both the earlier and more recent research identify moments of being blocked in their writing for lack of time, difficulties in comprehending complex material and both making it their own (understanding it) and relating it to their own research effectively rather than merely adding it in dislocated chunks. "Bittiness" in the writing process is a common worry. Several respondents note insights which enable academic writers to step back, see the pattern and shape of the whole of their research and writing, then clarify their arguments and slot the theories, arguments and data together.

And then there are these wonderful moments where things just slot into place, but only after a long engagement and in depth knowledge [...] then suddenly all relates to each other, like my argument is revealing itself to me. Of course this isn't the case [...] I can't really explain what happens, but it does feel like the pieces of my puzzle physically move towards each other. (1a, C)

Students identified plateaux, blocks, walls - using a range of kinaesthetic images to indicate difficulties of moving forwards in their writing, and then the liberation of illumination, of sudden clarity, of thinking, understanding, and expression. They emphasised the immediate felt nature of these moments of breakthrough in understanding and articulation using auditory, kinaesthetic and visual imagery. "I hit a brick wall"; "I stopped moving"; "I reached a plateau". Moments of clarity and understanding: "ding goes the bell"; "it clicked into place"; "a light went on"; "the fog cleared"; "a jigsaw piece coming together"; "a good feeling, like an adrenaline rush creating feelings of pride that you are going to write a good PhD"; "a peeling away of layers of arrogance"; "getting through a mountain"; "ideas coming together and learning to think more realistically"; and "a narrative weaving a pattern" (1b, D).

Students reported helpful practices included returning to the literature of the theory; thinking it through and really engaging with theory; working out its relevance to their work; sometimes drawing diagrams to clarify links, arguments, then working very hard to find the right words to express and clarify their understanding. The process of actually "grappling" with the words forced them through writing blocks. They were then more able to hone and perfect their expression of how they understood the ideas, arguments and links to their own work. This mixture of rereading, reconceptualising, and then reconfiguring in words is an example of conceptual threshold crossing (see 4, below). The writing first forces the understanding, then expresses it with finessing and honing. One comments:

If I get stuck on something then I write [...] it's in the same way of needing to speak to someone I guess, you know your brain works too quickly but if you slow it down by writing it out then sometimes it kind of becomes clearer. $(2, \mathrm{~B})$ 
In the early work on conceptual threshold crossing specifically related to writing, Maggi Savin-Baden and I (2009) found common stages in developing confident, conceptually robust, well-expressed writing. These developmental stages could be encouraged or "nudged" by supervisors and the students themselves, once they were aware of them; further, they enabled breakthroughs in thinking, as the writing improved, which we identified as conceptual threshold crossings, which can in turn develop and enhance writing for publication (Wisker, 2014).

Ways forward identified included reading to write; writing to write; managing the writing energy; and multitasking. Mimicry is also important at this stage (Bakhtin, 1981). Initially denigrated by postcolonial criticism as copying without understanding the behaviours of those in imperial power, I have reinterpreted mimicry by linking it to an awareness of the gate-keeping of the discipline language. Research writers, including doctoral students, need to understand and use that language, in order to gain entry into the ways in which their discipline expresses its research, arguments and contributions to knowledge (Wisker, 2014). Mimicry is an important stage in learning how to write the disciplinary discourse. One doctoral student recognises the value of mimicking to enable her argument: "I read my friend's PhD after my upgrade and then wrote my own ideas in a similar format, for an introductory chapter, just to feel like I had something concrete" (1b, E).

As they persevere and hone their work, students develop confidence in the quality of their writing, which is noted by supervisors:

Well, there are times when students start bringing you written work that begins to look like it could go in the final thesis, whereas initially it doesn't. In that sense, you know, there's a point at which the first time you say to a student, "Look you've written something here which I could see could go in the final thesis," that for them is a very significant moment, I think. (1a, F)

Signs of the transition to the writing expected in a thesis are noted by both students and supervisors. They include moving on from "bittiness" and "chunks" to coherence of logical order in the argument; from being overly comprehensive in the literature review and detail of the data analysis to clarifying the lens offered by carefully explained theories, and identifying emerging themes; then taking the theories as a lens throughout the research and as a structuring device for the discussion of the data/interpretation of the findings; using the themes as a structuring, clarifying device to enable the argument to flow from the data, and to emphasise the main important findings. Should the student be undertaking a thesis by publication with a theorised "wrap", it is probably the case that clarity is forced earlier so that individual publishable articles provide article-sized examples of the theorised lens, methodology, and thematically focused arguments through the data.

\section{Supervisor and other support in the transition and translation}

Supervisors and students commented on some of the processes which enable the clarity of view, the shaping and the translating of the research into theories and argument, backed by evidence. Some comment on the usefulness of taking a "helicopter view" and stepping back, presenting to others. Some mention specific forms of feedback which nudge thinking through modelling, open questions and challenge. Challenge is important, as one supervisor notes:

I think to challenge students in a constructive way, not just agree with everything they do; but if you think what a thesis will have to look like, what a viva eventually 
will be like and get used, you know, in a way to putting students on the spot, you know, in a positive, not an unpleasant way, but, you know, intellectually challenging students about their work and getting them to defend why they're taking a particular approach. (1a, G)

Immersion in the reading, plus discussion with the supervisor, peers, at conferences and in supportive groups, all help clarify the ideas, argument and significance of the work, which in turn feeds into the writing: "So the focusing of arguments, the narrowing down the lens, the theorists and critics, provide on your corner the torch which then can shine in that corner" (1a, H).

One supervisor explains the process of taking to pieces the constructs and expression in the work, using discussion and working with the writing at the same time. The excitement of breakthroughs in understanding and in their articulation is clearly an example of a conceptual threshold crossing:

I also think we touched on the importance of deconstructing the construct and that was quite a big discussion between us, that it's not always about building up but actually about pulling apart [...] in terms of writing and then collaging and I've done that with a few students and it was just great and the two of us just thought, I've never felt so alive almost. We can really feel our synapses buzzing. And that was an exciting moment. $(2, \mathrm{C})$

Other participants also suggested talking through parts of the work, presenting to each other in small communities in symposia or in regular lab group meetings. They comment on taking an overview, showing understanding of the shape, the main argument, the main questions and issues and the importance of the finding, extracting, and stepping back, encouraging clear, conceptual, shaped thinking about the main argument. They note ways in which the methodology and methods enable analysis and interpretation of the data to the main argument. The understanding is then transferred into the text itself.

\section{Breakthroughs and conceptual threshold crossings}

Themes 1, 2 and 3 above each foreground examples of conceptual threshold crossings in the research and writing, the transition between which is the main focus of this chapter. We have seen (a) how doctoral students identify, meet and cross these conceptual thresholds in their work, and (b) how examiners recognise this in the way successful doctoral writing conveys and convinces or "sells" their work. Now we turn to how doctoral students evidence and express their awareness of moving forward in their doctoral learning journeys and identities as researchers and writers, through confidence, ownership, agency and articulation.

Some doctoral students commented that breakthroughs in their writing confidence and articulation start to take place while writing the literature review (Wisker, 2015):

Physically, I experience these moments as "blurs" in time. Time doesn't matter anymore [...] it's incredibly fun, a feeling of elation of the mind-and eventually I emerge again, like stepping back into real time/space. And then I have hopefully written down all these thoughts and can come back to them, draw on them whenever I need to. $(1 \mathrm{~b}, \mathrm{I})$

For examiners, making connections between different areas of the field was important, signifying movement into new understanding, showing evidence of specific conceptual threshold crossings. They looked for writing that showed "deeper understanding 
of the issues" and "a step up in theoretical work" as evidence that students had "crossed thresholds" (2010, p. 37). They commented that they could see in the writing how the student had moved first from understanding to expressing it clearly, and that a breakthrough could occur through constructing a section, even after doing something mechanical. Then an "aha" moment happens: "it doesn't happen straight away and you can almost begin you know collecting data then suddenly have an 'aha' about something explored or read" (1a, J).

One examiner noted evidence of how doctoral students gain and express confidence in their writing:

\section{[...] in the writing, a marked shift in successive drafts where the writing becomes more authoritative, more bolder and what accompanies this is a reconfiguration of the self, the realisation that actually for a brief moment in time, I am actually the expert-this is the hallmark of advanced scholarship, it is a letting go of the supervisor and previous sense of self-a confidence, maturity. (1a, K)}

Another described the achievement of doctorateness as a "conceptual elegance of research design" with "an interesting story attached" (1a, K), recognising that this writing integrates analysis, theorising, development of a story and an argument. One commented on the link between the technical and conceptual processes of the $\mathrm{PhD}$ research and the expression of it in the writing, noting "a building on seminal work; selling, explaining and developing a concept" (1a L). Examiners in this earlier research also commented on the ways in which determining that the work was of publishable quality also provided indications of crossing conceptual thresholds and making a contribution to knowledge.

\section{Discussion}

Students evidence conceptual threshold crossings when they comment on moments of moving through liminal spaces of troublesomeness and confusion, riskiness (edgework) and questioning established views as first "blurs", and then "aha" moments, through their buzzing synapses. This leads to gaining perspective, breakthroughs in understanding and an awareness of their contribution to knowledge leading to further breakthroughs in expression in their writing. Some breakthroughs emerge in discussion with supervisors, and examiners comments on it when reading theses. Each identifies the student's realisation, evidence and expression of new authority and ownership in the work.

Writing a thesis is a patchy activity and an ongoing, iterative process of constantly refined expression, so that the (actually messy) research journey, the argument, the storyline, the findings and their significance, and the conceptual level thinking that underpins all of this is clear throughout. Reasons for and significance of the work, and the (tidied up) process of the research are highlighted both at the beginning and the end, showing why it was done this way, what of importance has been found and why that matters. The writing journey which accompanies and continues beyond the research turns those bitty bits that have been "written up" into something which is coherent, flowing, well organised and well expressed, and backs up its claims for knowledge with theory and evidence.

When producing a first draft of a thesis, students can have blockages and particular peculiarities, or stilted expression, as if only mimicking the words. In early drafts this is often quite obvious, because doctoral writers have been so immersed in literature, in wrestling with the methodology and methods, in struggling with vast quantities of often seemingly inchoate data which need theorising and arguing. The whole thesis is written and rewritten iteratively, first drafts to get the ideas out, to get the information down, to develop the argument, and subsequent drafts to go over and over it so that the whole hangs together, so the argument and 
the story are strung all the way through like beads, like a consistent theme in music, and so that the contribution to knowledge is clear throughout.

\section{Conclusions}

Doctoral students often encounter difficulties in translating their complex conceptual engagement and their messy research journey into articulate, confident writing. Supervisors can enable the writing by articulating this to students from the start, by setting up writing support and communities and by challenging student developmental through feedback on the text and in supervisory conversations.

Good writing habits, good time management, and awareness of producing different types of writing in different sections of the thesis, returning to the reading, returning to the theorists, and returning over and over to the writing are all useful strategies mentioned by students, supervisors and examiners. A good thesis is very readable, its contribution clear. The writing takes the messy research journey of stops and starts, confusions and breakthroughs, into something clear and focused. It enables that theorised lens, structured shape, focus on the journey, story and argument, and ensures that a reader can see that a significant contribution to knowledge has been made, owned and articulated.

\section{References}

Aitchison, C. (2009). Writing groups for doctoral education. Studies in Higher Education, 34(8), 905-916.

Aitchison, C., \& Guerin, C. (2014). Writing groups for doctoral education and beyond: Innovations in practice and theory. London: Routledge.

Aitchison, C., Kamler, B., \& Lee, A. (Eds.), (2010). Publishing pedagogies for the doctorate and beyond. Abingdon, UK: Routledge.

Aitchison, C., \& Lee, A. (2006). Research writing: Problems and possibilities. Teaching in Higher Education, 11(3), 265-278.

Bakhtin, M. (1981). The dialogic imagination: Four essays. Austin: University of Texas.

Bakhtin, M. (1986). Speech genres and other late essays. Austin: University of Texas Press.

Chihota, C. (2007). "The games people play": Taking on postgraduate identities in the context of writer circles. Journal of Applied Linguistics, 4(1), 131-136.

Elbow, P. (1973). Writing without teachers. London, Oxford, New York: Oxford University Press.

Harrison, L. (2006). "The meaning of PaperHeaDs". Extracts from email exchange July 2011, referring to journal entries, February 9, 2006.

Hartley, J., \& Fox, C. (2004) Assessing the mock viva: The experience of British doctoral students. Studies in Higher Education, 29(6), 727-738

Holbrook, A., Bourke, S., \& Cantwell, R. (2006). Using research candidate annual report data to examine aspects of supervision effectiveness". In M. Kiley \& G. Mullins (Eds.), Quality in Postgraduate Research: Knowledge Creation in Testing Times, (pp. 84-98). Canberra: CEDAM, Australian National University.

Holbrook, A., Bourke, S., Lovat, T., \& Dally, K. (2005). An investigation of inconsistencies in $\mathrm{PhD}$ examination decisions". Proceedings of the Australian Association for Research in Education Conference, University of Melbourne, November 2004.

Ivanic, R. (1998). Writing and identity: The discoursal construction of identity in academic writing. Amsterdam: John Benjamins.

Johansson, T., Strandler, O., Claesson, S., Saalman, E., \& Wisker, G. (2014). PhD. supervision as an emotional process - critical situations and emotional boundary work. Pertanika Journal of Social Science and Humanities, 22(2), June 2014 
Johnson, L., Lee, A., \& Green, B. (2000). The PhD and the autonomous self: Gender, rationality and postgraduate pedagogy. Studies in Higher Education, 25(2), 45, 13547.

Kamler, B., \& Thomson, P. (2006). Helping doctoral students write: Pedagogies for doctoral supervision. London: Routledge.

Kiley, M., \& Mullins, G. (2002). "It's a PhD, not a Nobel Prize": How experienced examiners assess research theses. Studies in Higher Education, 27(4).

Kiley, M., \& Wisker, G. (2009). Threshold concepts in research education and evidence of threshold crossing. Higher Education Research and Development, 28(4), November, 431-441.

Lillis, T., \& Scott, M. (2007). Defining academic literacies research: Issues of epistemology, ideology and strategy. Journal of Applied Linguistics, 4(1), 5-32.

Lyng, S. (1990). A social psychological analysis of voluntary risk-taking. American Journal of Sociology, 95(4), 851-886.

Manathunga, C. (2007). Intercultural postgraduate supervision: Ethnographic journeys of identity and power. In D. Palfreyman \& D.L. McBride (Eds.), Learning and teaching across cultures in higher education, First edition (pp.93-113). New York: Palgrave.

Manathunga, C. (2014). Intercultural Postgraduate Supervision: Reimagining Time, Place and Knowledge. London: Routledge.

Maybin, J. (2001). Language, struggle and voice: The Bakhtin/Volosinov writings. In M. Wetherell, S. Taylor \& S.J. Yates (Eds.), Discourse theory and practice: A reader (pp.64-71). London: Sage.

Meyer, J.H.F., \& Land, R. (2005). Threshold concepts and troublesome knowledge (2): Epistemological considerations and a conceptual framework for teaching and learning. Higher Education 49(3), 373 (16).

Morris, C., \& Wisker, G. (2011). Troublesome encounters: Strategies for managing the wellbeing of masters and doctoral education students during their learning process. Retrieved from: http://escalate.ac.k/6828

Murray, R. (2005). Writing for academic journals. Maidenhead: Open University Press.

Strandler, O Johanssen, T., Wisker, G., \& Claesson, S. (2014). Supervisor or counsellor? Emotional boundary work in supervision. International Journal of Researcher Education (forthcoming).

Sword, H. (2009). Writing higher education differently: A manifesto on style. Studies in Higher Education 34(3), 319-336.

Thesen, L. (2013). Risk in postgraduate writing: Voice discourse and edgework. Cristal 1(1), 105, 107, 117-9.

Winter, R. (1993). Continuity and progression: Assessment vocabularies for higher education, unpublished research report data. Chelmsford: Anglia Polytechnic University, Faculty of Health and Social Work.

Winter, R., Griffiths, M., \& Green, K. (2000). The "academic" qualities of practice: What are the criteria for a practice-based PhD? Studies in Higher Education, 25(1), 25-37.

Wisker, G. (2005, 2012). The good supervisor: Supervising postgraduate and undergraduate research for doctoral theses and dissertations. London: Palgrave.

Wisker, G. (2015). Getting published: Academic publishing success. London: Palgrave Macmillan.

Wisker, G. (2015). Developing doctoral authors: Engaging with theoretical perspectives through the literature review. Innovations in Education and Teaching International special edition on doctoral education, 57(1).

Wisker, G. and Kiley, M. (2012). Professional Learning: Lessons for Supervision from Doctoral Examining. International Journal for Academic Development, 1-14. 
Wisker, G., Morris, C., Cheng, M., Masika, R., Warnes, M., Lilly, J., Trafford, V., \& Robinson, G. (2007-2010). Doctoral learning journeys-Final report of the NTFSfunded project, p. 37. Retrieved from: http://www.heacademy.ac.uk/resources/detail/ntfs/Projects/Doctoral_Learning_Journe ys (2011).

Wisker G., \& Robinson, G. (2009). Encouraging postgraduate students of literature and art to cross conceptual thresholds. Innovations in Education and Teaching International, 46(3), 317-30.

Wisker, G., \& Robinson, G. (2013). Doctoral "orphans": Nurturing and supporting the success of postgraduates who have lost their supervisors. Higher Education Research and Development, 32, (2), 300-313.

Wisker, G., Robinson, G., Trafford, V., Warnes, M., \& Creighton, E. (2003). From supervisory dialogues to successful PhDs: Strategies supporting and enabling the learning conversations of staff and students at postgraduate level. Teaching in Higher Education 8(3), 383-97.

Wisker, G., \& Savin-Baden, M. (2009). Priceless conceptual thresholds: Beyond the "stuck place" in writing. London Review of Education 7(3), 235-24. 